\title{
Plasmodium berghei circumsporozoite protein encapsulated in oligomannose-coated liposomes confers protection against sporozoite infection in mice
}

\author{
Mohamad Alaa Terkawi', Yasuhiro Kuroda², Shinya Fukumoto', Sachi Tanaka', Naoya Kojima² \\ and Yoshifumi Nishikawa ${ }^{1 *}$
}

\begin{abstract}
Background: The design and development of an effective malaria vaccine against the pre-erythrocytic and erythrocytic-stages of infection present a great challenge.

Methods: In the present study, protective efficacy of oligomannose-coated liposome (OML)-entrapped merozoite and sporozoite antigens against Plasmodium berghei challenge infection in BALB/c mice was evaluated.

Results: Subcutaneous immunization with truncated merozoite surface protein 1 entrapped with OML (OML-PbMSP1) prolonged survival, but failed to protect the mice from erythrocytic-stage infection, despite the antigen-specific antibody responses induced by the immunization regimen. In contrast, immunization with circumsporozoite protein entrapped with OML (OML-PbCSP) elicited antigen-specific humoral and cellular responses, which correlated with substantial protection against sporozoite challenge infections.
\end{abstract}

Conclusions: The current results represent the use of an oligomannose-coated liposome-based vaccine against pre-erythrocytic and erythrocytic stages malaria infection. This approach may offer a new vaccination strategy against malaria infection.

Keywords: Vaccine, Plasmodium berghei, Oligomannose-coated liposome

\section{Background}

Malaria remains the most important parasitic disease of humans, affecting $40 \%$ of the world's population and causing over 600,000 deaths annually [1]. Vaccination to prevent the infection is believed to be the most realistic approach for reducing malaria morbidity and mortality. Over the last decades, the gold standard for malaria vaccine development has been immunization with radiationattenuated sporozoites [1]. Recent study has shown that genetic attenuated sporozoites by gene deletion may offer better strategy for development of malaria vaccine [2]. Although this vaccine strategy offers sterile protection

\footnotetext{
*Correspondence: nisikawa@obihiro.ac.jp

${ }^{1}$ National Research Center for Protozoan Diseases, Obihiro University of Agriculture and Veterinary Medicine, Inada-cho, Obihiro, Hokkaido 080-8555, Japan

Full list of author information is available at the end of the article
}

against infection, several problems exist that have hampered its use including the cost, dose standardization, production, sporozoite irradiation, and immunization-related issues $[3,4]$.

The most advanced malaria vaccine to date, RTS,S, comprises a portion of the Plasmodium falciparum circumsporozoite protein (CSP) central repeat (NANP) and C-terminal region, which contains $\mathrm{T}$ cell epitopes fused to the hepatitis B virus surface antigen. Since early 1996, several adjuvant formulations of this vaccine have been tested against live sporozoite challenge in volunteers, with the highest protective efficacies (30-50\%) observed with an adjuvant containing monophosphoryl lipid A and QS21 (a derivative of Quill A) [5,6]. In addition, the prime-boost regimen for the modified vaccinia virus Ankara (MVA) and the new fowlpox FP9 strain, both of which encode the Plasmodium falciparum thrombospondin-related adhesion 
protein (TRAP), offered some degree of protection in African volunteers [7]. Asexual erythrocytic-stage vaccines, tested in clinical trials, also afford some degree of protection [8]. Two asexual-stage proteins, merozoite surface protein 1 (PfMSP1) and apical membrane antigen 1 , are the most extensively studied candidates for the development of erythrocytic-stage vaccines $[8,9]$. Remarkably, all candidates for subunit vaccines against malaria target the parasite invasion process into the host cells. Despite the promising levels of protection induced by these vaccines, none appear potent enough to completely prevent infection in the majority of recipients. Therefore, further vaccine development research is required to obtain the ultimate goal of complete prevention of malarial infection.

Accumulating evidence shows that protective immunity against liver-stage malaria parasites requires Th1-type immune responses; these responses orchestrate optimal $\mathrm{CD}^{+} \mathrm{T}$ cell-mediated cytotoxicity responses, $\mathrm{CD}^{+} \mathrm{T}$ cells act as the principal effector cells for elimination of infected hepatocytes, and induction of neutralizing antibodies for trapping extracellular sporozoites [10,11]. Elimination of erythrocytic-stage parasites is dependent on $\mathrm{CD}^{+}{ }^{+} \mathrm{T}$ cells; they release cytokines that activate other effector cells to clear parasite-infected red blood cells $(\mathrm{pRBCs})$ and maintain protective antibody production. The mechanisms by which antibodies are effective include blockading the invasion of free merozoites into RBCs and cytophilic antibody-dependent cellular killing [12]. Therefore, ideal vaccines for pre-erythrocytic and erythrocytic-stage malaria should induce a protracted Th1 memory response coupled with a sufficiently robust parasite-neutralizing antibody response $[12,13]$. Such responses are achievable using appropriate immunization regimens in conjunction with novel adjuvants and vaccine delivery vehicles [14].

Oligomannose-coated liposomes (OML) are a novel adjuvant capable of inducing Th1 immune responses and cytotoxic $\mathrm{T}$ lymphocytes (CTLs) specific for the encased antigen. OMLs are taken up preferentially by phagocytic cells, such as dendritic cells and macrophages, through mannose-binding lectin receptors and complement receptor type 3, which leads to antigenpresenting cell (APC) maturation, expression of costimulatory major histocompatibility complex (MHC) class I and II molecules, and migration of APCs into lymphoid tissues from peripheral tissues. Consequently, APCs introduce the encapsulated protein to $\mathrm{CD}_{4}^{+}$and $\mathrm{CD}^{+} \mathrm{T}$ cells, which generate encased-antigen-specific Th1 cells and CTL responses in the host $[15,16]$. Indeed, the protective effects of OML-based vaccines have been reported for a variety of protozoan infections, including those caused by Neospora caninum, Leishmania major and Toxoplasma gondii [17-21]. In the present study, the protective effects of immunization with OML-entrapped C-terminal-merozoite surface protein 1 (OML-PbMSP1) and truncated circumsporozoite protein (OML-PbCSP) against Plasmodium berghei merozoite and sporozoite challenge in BALB/c mice were investigated. The truncated regions of each antigen used for OML encapsulation were designed based on the earlier vaccination trials with protective effects or their role in host cells invasion [22]. Moreover, truncated region of PbCSP was designed based on the target region of RTS,S vaccine containing CD8 epitopes and repeat region of CSP [5,23]. The present study revealed that the OML-PbCSP immunization regimen conferred a significant degree of protection against the pre-erythrocytic stage of $P$. berghei.

\section{Methods}

\section{Ethics statement}

This study was performed in strict accordance with the recommendations in the Guide for the Care and Use of Laboratory Animals of Ministry of Education, Culture, Sports, Science and Technology, Japan. The protocol was approved by the Committee on the Ethics of Animal Experiments of the Obihiro University of Agriculture and Veterinary Medicine (Permit number 24-17, 25-66). All surgery was performed under isoflurane anesthesia, and all efforts were made to minimize animal suffering.

\section{Mice}

Seven-week-old BALB/c mice purchased from Clea (Tokyo, Japan) were housed under specific-pathogen-free conditions in the animal facility of the National Research Center for Protozoan Diseases at Obihiro University of Agriculture and Veterinary Medicine, Obihiro, Japan. All mice used in the present study were treated under the guiding principles for the care and use of research animals promulgated by Obihiro University of Agriculture and Veterinary Medicine.

\section{Parasites}

Plasmodium berghei (ANKA strain) was obtained from the Department of Molecular Parasitology, Ehime University School of Medicine, Japan and maintained by mosquito transmission in Anopheles stephensi interspersed by a maximum of two serial passages in BALB/c mice. The pRBCs were recovered from frozen pRBC stock by intraperitoneal (i.p.) passage inoculations in mice. Sporozoites were obtained by dissection of salivary glands from $P$. berghei-infected female mosquitos 21 days after taking blood meals from $P$. berghei infected mice.

\section{Recombinant proteins and liposome preparation}

Recombinant proteins comprising truncated regions of PbMSP1 (Leu 1609 -Ser 1768 , GenBank accession number: $\mathrm{AAC} 28871)$ and PbCSP (Asn $201-\mathrm{Asn}_{347}$, GenBank accession 
number: P23093.1) were produced in Escherichia coli as glutathione S-transferase (GST) fusion proteins. Briefly, the coding regions of the targeted genes were amplified from $P$. berghei ANKA genomic DNA with specific primer sets designed from the GenBank sequences: these were 5'-AC GGA TCC AGT ATT ACC ACC GAG CAG AA-3', which includes a BamHI restriction enzyme site (boldface), and 5'AG CTC GAG TTA GCT GGA AGA GCT ACA GAA-3', which includes a XhoI restriction enzyme site (boldface) for PbMSP; and 5'-AA GGA TCC CAG CCA CAA CCA CAG CCA GGT-3', which includes a BamHI restriction enzyme site (boldface), and 5'-GG CTC GAG TTA TGA ACA TTT ATC CAT TTT-3', which includes a XhoI site (boldface) for PbCSP. PCR products were digested with the appropriate restriction enzymes and then ligated into a pGEX-4 T1 (GE Healthcare, Buckinghamshire, UK) expression vector, which had been digested with the same set of restriction enzymes. The nucleotide sequences of the PbMSP1- and PbCSPpositive plasmid inserts were determined using an ABI 3100 DNA sequencer (Applied Biosystems, Foster City, CA, USA). Recombinant proteins were expressed in large-scale DH5 $\alpha$ strain E. coli cultures (Takara Bio Inc., Osaka, Japan) and purified by Glutathione-Sepharose $4 \mathrm{~B}$ beads (GE Healthcare). Purified recombinant proteins were treated with thrombin protease (GE Healthcare) to digest the GST tag and then subjected to endotoxin removal using the membrane filter, Acrodisc ${ }^{\oplus}$ Unite (Pall Life Sciences, Ann Arbor, MI, USA). The purity and quantity of the recombinant proteins were tested by sodium dodecyl sulphate polyacrylamide gel electrophoresis (SDS-PAGE) stained with Coomassie Brilliant Blue R250 (MP Biomedicals Inc., Illkirch-Graffenstaden, France) and by a BCA protein assay kit (Thermo Fisher Scientific, Inc. Rockford, IL, USA). Single bands $(20-\mathrm{kDa}$ and $14-\mathrm{kDa})$ corresponding to each recombinant protein (PbMSP-1 and $\mathrm{PbCSP}$, respectively) were observed with SDS-PAGE (Figure 1). Thereafter, OMLs were prepared for recombinant protein entrapment as described previously [17-21], and the amount of entrapped antigen was measured using a modified Lowry protein assay reagent (Pierce, Rockford, IL, USA).

\section{Immunization and challenge infections}

Seven-week-old female BALB/c mice were immunized subcutaneously (s.c.) with $3 \mu \mathrm{g}$ of OML-PbMSP1 or OML-PbCSP. In parallel, the other groups of mice were immunized with $3 \mu \mathrm{g}$ of the corresponding naked protein, or OML alone. Two boosts with the same dose of protein were administered s.c. at 14-day intervals. In separate experiments, modified immunization regimens that included boosting once before infection and immunization with $1 \mu \mathrm{g}$ of OML-PbCSP were performed. In all experiments, each mouse received a $100 \mu \mathrm{l}$ immunization, adjusted by adding phosphate-buffered saline (PBS). Serum samples $(15 \mu \mathrm{l})$ were serially obtained from the tail vein of each

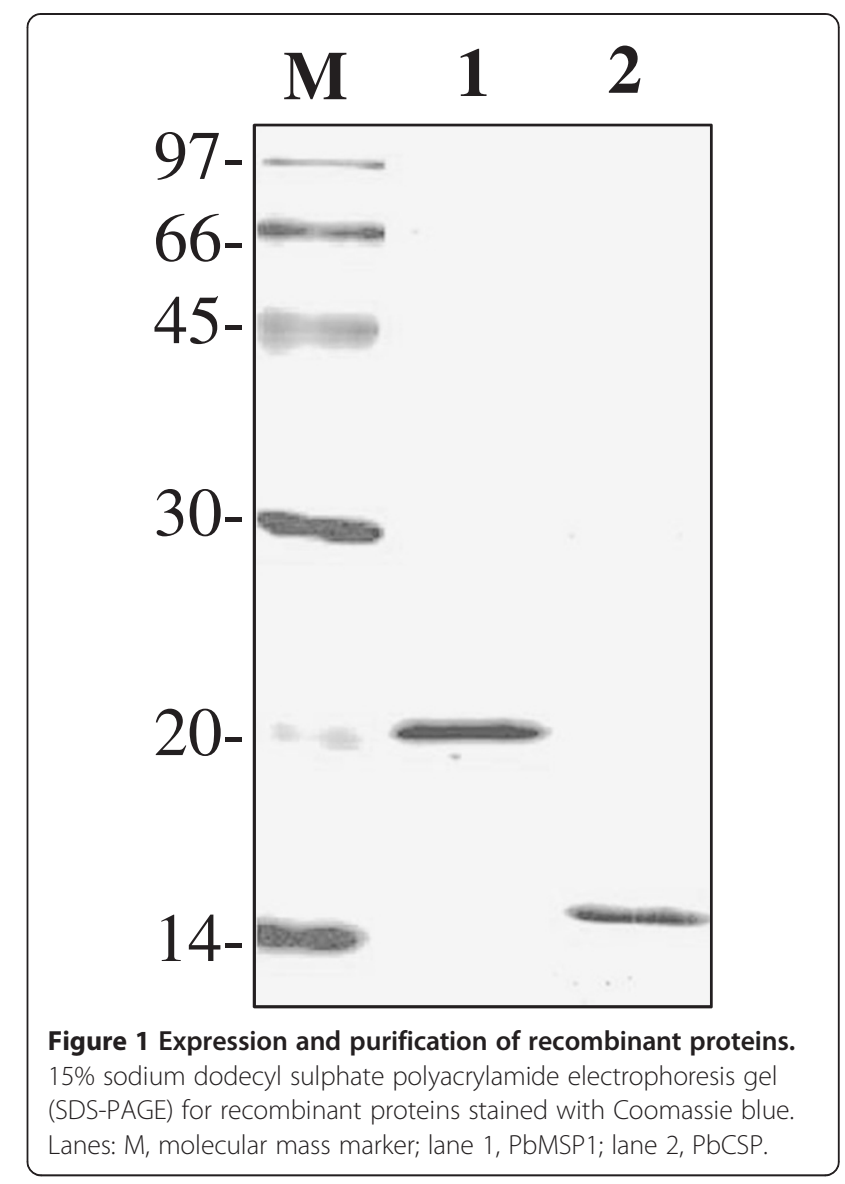

mouse at $0,14,28$ and 42 days post- $1^{\text {st }}$ immunization. The specific reactivity of immune sera was confirmed by using indirect fluorescence assay with pRBCs or purified sporozoites. Thereafter, mice immunized with PbMSP1 were infected with an intraperitoneal (i.p.) inoculation of $1 \times 10^{5}$ fresh pRBCs, while mice immunized with PbCSP were infected s.c. (into the loose skin over the neck and shoulders) with a live inoculum of $2 \times 10^{3}$ sporozoites/ mouse 14 days after the last boost. Parasitemia and survival rates were monitored over a 30-day period.

\section{Measurement of antigen-specific antibodies}

An enzyme-linked immunoabsorbent assay (ELISA) was performed to examine the immunogenicity of the immunization regimen as described previously [18,20,21]. Briefly, $50 \mu \mathrm{l}$ of purified antigen (at a final concentration of $0.1 \mu \mathrm{M}$ ) was coated onto a 96-well microtiter plate (Nunc, Roskilde, Denmark) and incubated overnight at $4^{\circ} \mathrm{C}$ with a carbonate-bicarbonate buffer $(\mathrm{pH}$ 9.6). Plates were blocked with $100 \mu \mathrm{l}$ of PBS-3\% skimmed milk (3\% SMPBS) per well and then incubated at $37^{\circ} \mathrm{C}$ for $1 \mathrm{~h}$ with 50 $\mu \mathrm{l}$ of each serum sample diluted 1:100 or serially diluted from 1:100 to $1: 51,200$ in 3\% SM-PBS. After washing six times with PBS containing $0.05 \%$ Tween 20, the plates were incubated at $37^{\circ} \mathrm{C}$ for $1 \mathrm{~h}$ with horseradish 
peroxidase-conjugated anti-mouse IgG, IgG1 or IgG2a (Bethyl Laboratories, Montgomery, TX, USA) diluted in $3 \%$ SM-PBS to $1: 4,000$. Thereafter, the plates were washed with $100 \mu \mathrm{l}$ substrate solution (0.1 M citric acid, $0.2 \mathrm{M}$ sodium phosphate, $0.003 \% \mathrm{H}_{2} \mathrm{O}_{2}$ ), and 0.3 $\mathrm{mg} / \mathrm{ml}$ 2,2'-azide-bis [3-ethylbenzthiazoline-6-sulfonic acid] (Sigma St. Louis, MO, USA) was added to each well. The mean optical density (OD) of the wells was determined by measurement at a wavelength of $415 \mathrm{~nm}$ using an MTP-500 microplate reader (Corona Electric, Tokyo, Japan). Endpoint titers were expressed as the reciprocal of the highest sample dilution for which the OD was equal or greater than the cut-off values calculated based on the average ODs of the pre-immune mouse sera plus three standard deviations.

\section{In vitro splenocyte stimulation assays}

Spleens were harvested 14 days after the last booster, and a single-cell suspension of splenocytes was plated into 96-well microplates at $5 \times 10^{5} / 200 \mu \mathrm{l} /$ well in RPMI 1640 medium (Sigma) supplemented with $5 \%$ foetal bovine serum $[18,21]$. Cultures were stimulated by adding 10 or $50 \mu \mathrm{g} / \mathrm{ml}$ of purified $\mathrm{PbCSP}$, or $0.5 \mu \mathrm{g} / \mathrm{ml}$ of concanavalin A. After incubation for $48 \mathrm{~h}$ at $37^{\circ} \mathrm{C}$, the culture supernatants were collected and assayed for IFN- $\gamma$, IL-4 and IL-10 production using commercial ELISA kits (Pierce Biotechnology, Rockford, IL, USA), according to the manufacturer's instructions.

\section{Statistical analysis}

The significant differences among the means of all variables were examined by a one-way analysis of variance followed by Tukey's multiple comparison test (GraphPad Prism 5, GraphPad Software Inc., San Diego, CA, USA). Results were considered to be statistically significant when $\mathrm{p}$ was $<0.05$.

\section{Results}

Immunization with OML-PbMSP1 prolonged survival but fails to protect mice from erythrocytic-stage challenge infection with Plasmodium berghei

To evaluate the immunogenicity of the OML-PbMSP1 immunization, sera were serially sampled prior to and after each immunization, and the antibody responses were examined by ELISA using PbMSP1. Of note, OML-PbMSP1 induced highly specific antibody responses in the mice consisting of IgG1 and IgG2a isotypes (Figure 2A,B). Indeed, the PbMSP1-specific antibodies induced by immunization with OML-PbMSP1 were significantly greater than those induced by naked antigen over the course of the immunizations, and it was found that the titers increased at least 10 -fold after the third immunization (Table 1 and Figure 2A,B). No PbMSP1-specific antibody responses were detected in mice that received OML or no immunization. Thereafter, to evaluate the protective efficacy of OML-PbMSP1 against erythrocytic-stage infection, mice were infected with pRBCs and their parasitemia and survival rates were monitored over a 30 -day period. Mice showed a patent parasitemia by day 3 post-infection and succumbed to malaria infection within one month (Figure 2C,D). Notably, the OML-PbMSP1-immunized mice had a delay in their onset of parasitemia $(36.4 \%$, $4 / 11$ mice) and prolonged survival as compared with the other groups of mice (Table 1).

\section{Immunization with OML-PbCSP confers substantial protection against liver-stage Plasmodium berghei infection} The immunization regimen with either OML-PbCSP $(3 \mu \mathrm{g})$ induced strong and specific antibody responses to the antigen, which consisted of IgG1 and IgG2a isotypes (Figure 3A-B). Antigen-specific IgG1 and IgG2a were significantly greater in mice immunized with OML$\mathrm{PbCSP}$ than in mice immunized with the corresponding naked antigen over the course of the immunizations (Figure 3A-B). No specific-PbCSP antibody responses were observed in mice that received OML or no immunization. Consistently, antibody titration against antigen revealed that the IgG1 and IgG2a titers increased at least 20-fold and 16-fold, respectively, in the OML-based antigen-immunized mice as compared with those that received the corresponding naked antigen (Table 2). These results showed that the immunization regimen for OML-PbCSP was capable of inducing robust humoral responses consisting of IgG1 and IgG2a isotypes. Next, immunized mice were infected s.c. with a live inoculum of $2 \times 10^{3}$ sporozoites/mouse 14 days after their last boost, after which their parasitemia and survival rates were monitored over a 30 -day period. Notably, 54\% of the OML-PbCSP-immunized mice showed complete sterile protection, as defined by the absence of patent parasitemia over the study period. In contrast, the OML-immunized control group showed 9.1\% protection (Table 2). No protection was observed in the mice that received the naked antigen immunization regimen or no immunization (Table 2). Moreover, comparison of the parasitemia curves revealed that the OML-antigen-immunized mice, which had pRBCs, experienced at least a 1-day delay in the onset of parasitemia as compared with mice immunized with naked antigen or OML alone, or those that were not immunized (Table 2). Moreover, antibody titer of antiPbCSP-specific IgG2a in protected mice by OMLPbCSP immunization tended to be higher than those in susceptible mice received same immunization (protected; $3520 \pm 787$, unprotected; $1733 \pm 1753, P=0.0504$ ), while there was no significant difference in the antibody titer of the specific IgG1. Furthermore, use of a modified immunization regimen comprising OML-PbCSP with a single boost resulted in a reduced protection rate as noted 
A
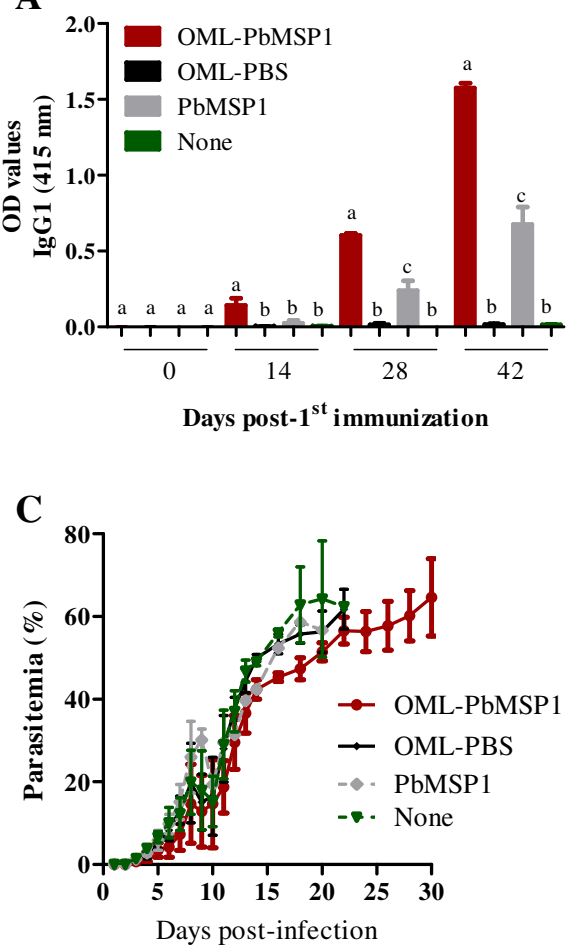

B

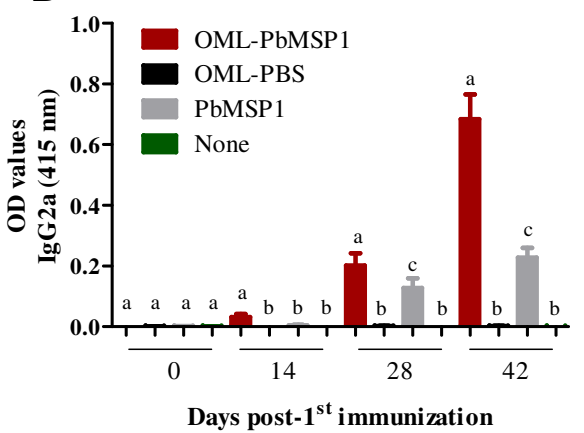

D

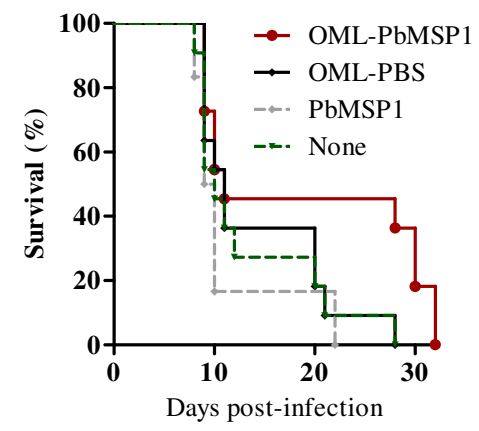

Figure 2 Efficacy of immunization with OML-PbMSP1. ELISA detection of antigen-specific $\lg G 1$ (A) and $\lg$ G2a (B) in mice immunized with recombinant PbMSP1 over the course of immunization. The mean optical density (OD) was determined at a wavelength of $415 \mathrm{~nm}$. Each bar represents the mean \pm SD for used mice per group and results are representative of two independent experiments. Different superscript letters indicate statistically significant differences $(P<0.05)$ among groups at each time-point as determined by a one-way analysis of variance followed by Tukey's multiple comparison test. Parasitemias (C) and survival rates (D) after challenge infection with pRBCs. Each bar represents the mean \pm SD for 11 mice per group (only 6 mice for PbMSP1) and results are from two pooled independent experiments. Mice were either immunized by OML-PbMSP1 (OML-PbMSP1), OML alone (OML-PBS), or naked PbMSP1 (PbMSP1), or not immunized (None).

as $16.7 \%$ (Table 2). The immunization regimen of OML$\mathrm{PbCSP}$ containing $1 \mu \mathrm{g}$ antigen with two boots resulted in $66.7 \%$ complete protection in mice. Nonetheless, lower protection correlated with reduced antibody responses was observed in OML-PbCSP-immunized mice with single boost (Table 2). These results show that the immunization regimen with OML-PbCSP conferred a significant degree of protection against pre-erythrocytic stage infection of $P$. berghei in the BALB/c mice.

Additionally, to gain better insight into the cellular responses induced by the immunization regimen with OML-PbCSP, splenocytes were prepared from immunized mice and stimulated in vitro for cytokine detection. Strikingly, splenocytes from the OML-PbCSP-immunized mice

Table 1 Effects of OML-PbMSP1 immunization against $P$. berghei merozoite challenge

\begin{tabular}{|c|c|c|c|c|c|}
\hline \multirow[t]{2}{*}{ Immunization } & \multicolumn{2}{|c|}{ Antibody titration* } & \multirow{2}{*}{$\begin{array}{c}\text { Infected/total }\left[I^{\text {st }}+2^{\text {nd }} \text { trials }\right] \\
\text { (Number) }\end{array}$} & \multirow{2}{*}{$\begin{array}{c}\text { Survival* } \\
\text { (Day) }\end{array}$} & \multirow{2}{*}{$\begin{array}{c}\text { Protection }^{\dagger} \\
(\%)\end{array}$} \\
\hline & IgGI & $\operatorname{lgG} 2 a$ & & & \\
\hline OML-PbMSP1 & $11636 \pm 5593^{\dagger+}$ & $2182 \pm 1604^{\dagger \dagger}$ & $11 / 11[(5 / 5)+(6 / 6)]$ & $19.1 \pm 10.9$ & 0 \\
\hline PbMSP1 & $1333 \pm 413$ & $283 \pm 132$ & $6 / 6$ & $14.3 \pm 6.7$ & 0 \\
\hline OML-PBS & 0 & 0 & $11 / 11[(5 / 5)+(6 / 6)]$ & $11.3 \pm 5.3$ & 0 \\
\hline None & 0 & 0 & $11 / 11[(5 / 5)+(6 / 6)]$ & $11.8 \pm 5.2$ & 0 \\
\hline
\end{tabular}

${ }^{*}$ Antigen-specific $1 \mathrm{gG} 1$ and IgG2a detected by ELISA with recombinant PbMSP1 at 14 days after the last boost. Each value represents the mean titer of antibody \pm SD per mouse group.

*Each value represents the average survival day \pm SD per mouse group.

${ }^{\dagger}$ Mice were scored as protected when parasitemia was not observed over a 30-day period.

${ }^{+t}$ Indicates statistically significant differences between the antibody titers of OML-PbMSP1-immunized mice and those of the corresponding mice immunized with naked antigen.

Results represent pooled data of two independent experiments. 
A

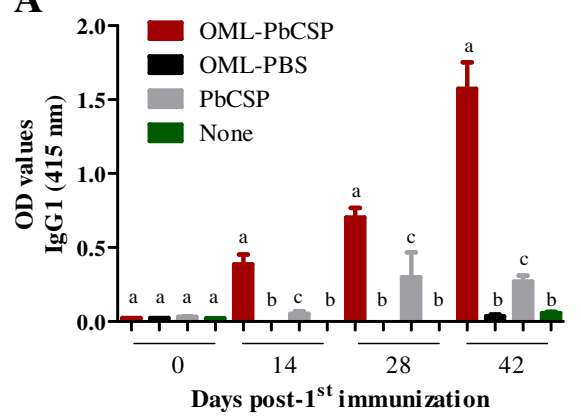

B

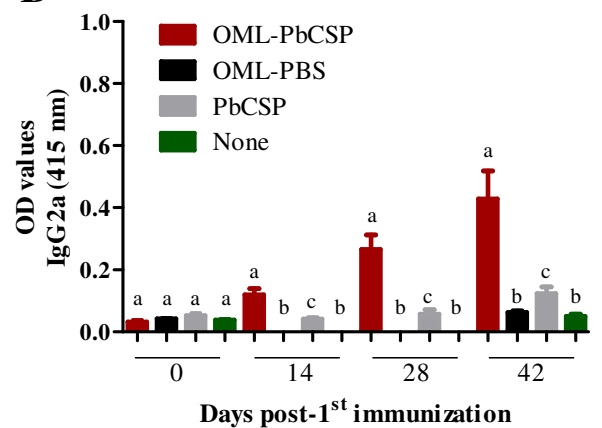

Figure 3 Humoral responses in mice to immunization with OML-PbCSP. ELISA detection of antigen-specific $\operatorname{lgG} 1$ (A) and $\lg G 2 \mathrm{a}$ (B) in mice immunized with recombinant PbCSP. The mean optical density (OD) was determined at a wavelength of $415 \mathrm{~nm}$. Each bar represents the mean \pm SD for used mice per group and results are representative of two independent experiments. Different superscript letters indicate statistically significant differences $(P<0.05)$ among groups at each time-point as determined by a one-way analysis of variance followed by Tukey's multiple comparison test. Mice were either immunized by OML-PbCSP (OML-PbCSP), OML alone (OML-PBS), naked PbCSP (PbCSP) or not immunized (None). Different superscript letters indicate statistically significant differences $(P<0.05)$ among groups as determined by a one-way analysis of variance followed by Tukey's multiple comparison test.

released high levels of IFN- $\gamma$ after stimulation with $\mathrm{PbCSP}$ at concentrations of $10 \mu \mathrm{g} / \mathrm{ml}$ or $50 \mu \mathrm{g} / \mathrm{ml}$ (Figure $4 \mathrm{~A}$ ). In contrast, the IFN- $\gamma$ levels of the splenocytes from OML- or naked PbCSP-immunized mice as well as non-immunized mice after stimulation with the same antigen were below the limits of detection of the kits. Likewise, IL-4 was detected in cultures from the antigen-immunized mice after stimulation with $50 \mu \mathrm{g} / \mathrm{ml}$ PbCSP (Figure 4B). However, detected IL-4 levels in OML-PbCSP-immunized mice were significantly higher than those detected in naked antigen immunized mice (Figure 4B). Levels of IL-10 were not significantly different in all cultures after stimulation with $50 \mu \mathrm{g} / \mathrm{ml} \mathrm{PbCSP}$ (Figure 4C). Stimulation with concanavalin A, which acted as a positive control, resulted in high levels of IFN- $\gamma$, IL-4 and IL-10 in all of the cultures (Figure 4).

\section{Discussion}

In general, protection against erythrocytic-stage infection is thought to be mediated by $\mathrm{CD} 4^{+} \mathrm{T}$ cells, which orchestrate the activation of effector cells and maintain the production of protective antibodies. Humoral responses have been shown to play an indispensable role in protection against malaria by blocking merozoite invasion and neutralizing pRBCs for macrophage phagocytosis [24,25]. However, subunit vaccine failure against $P$. berghei erythrocyte-stage parasite challenge has often been observed [26,27], with only a few trials showing some degree of protection in mouse model $[22,28]$. The difficulties in achieving protection against $P$. berghei might be caused by suppression or evasion of the immune system during the infection. In fact, alongside the sequestration of parasites in blood capillaries, erythrocytic-stage $P$. berghei can

Table 2 Effects of OML-based antigen immunization against $P$. berghei sporozoite challenge

\begin{tabular}{|c|c|c|c|c|c|c|c|}
\hline \multirow[t]{2}{*}{ Antigen } & \multicolumn{2}{|c|}{ Immunization } & \multicolumn{2}{|c|}{ Antibody titration* } & \multirow{2}{*}{$\begin{array}{c}\text { Infected/total } \\
{\left[1^{\text {st }}+2^{\text {nd }} \text { trials }\right] \text { (Number) }}\end{array}$} & \multirow[t]{2}{*}{ Parasitemia* } & \multirow[t]{2}{*}{ Protection $^{\dagger}(\%)$} \\
\hline & Dose & Boost & $\operatorname{lgG1}$ & $\operatorname{lgG} 2 a$ & & & \\
\hline \multirow[t]{2}{*}{ OML-PbCSP } & $3 \mu \mathrm{g}$ & 2 & $10666.7 \pm 3304.9^{t \dagger}$ & $3466.7 \pm 1573.1^{\dagger \dagger}$ & $5 / 11[(2 / 5)+(3 / 6)]$ & $6.40 \pm 0.55$ & $54 \%(P=0.004)$ \\
\hline & $1 \mu \mathrm{g}$ & 2 & $4900.0 \pm 2038.6^{\dagger \dagger}$ & $1200.0 \pm 979.8^{\dagger \dagger}$ & $2 / 6$ & $8.50 \pm 2.10$ & $66.7 \%(P=0.002)$ \\
\hline \multirow[t]{2}{*}{ OML-PbCSP } & $3 \mu \mathrm{g}$ & 1 & $1733.3 \pm 786.5^{\dagger \dagger}$ & $600.0 \pm 219.1^{\dagger \dagger}$ & $5 / 6$ & $6.50 \pm 1.00$ & $66.7 \%(P=0.002)$ \\
\hline & $1 \mu \mathrm{g}$ & 1 & $533.3 \pm 206.6^{\dagger \dagger}$ & $266.7 \pm 103.3^{\dagger \dagger}$ & $4 / 6$ & $6.60 \pm 1.34$ & $33.3 \%(P=0.041)$ \\
\hline $\mathrm{PbCSP}$ & $3 \mu \mathrm{g}$ & 1 & $433.3 \pm 196.6$ & $166.7 \pm 51.6$ & $11 / 11[(5 / 5)+(6 / 6)]$ & $5.83 \pm 0.98$ & $0 \%$ (N.A.) \\
\hline OML-PBS & & 2 & 0 & 0 & $10 / 11[(5 / 5)+(5 / 6)]$ & $5.50 \pm 1.40$ & $5.9 \%(P=0.413)$ \\
\hline None & & 0 & 0 & 0 & $11 / 11[(5 / 5)+(6 / 6)]$ & $5.09 \pm 1.04$ & $0 \%$ \\
\hline
\end{tabular}

*Antigen-specific lgG1 and lgG2a detected by ELISA with recombinant PbCSP 14 day after the last boost. Each value represents the mean antibody titer \pm SD per mouse group.

*Each value represents tie mean day of parasitemia onset \pm SD per mouse group.

${ }^{+\dagger}$ Indicates a statistically significant difference between the antibody response of the OML-based antigen-immunized group to those of the corresponding group immunized with naked antigen.

${ }^{\dagger}$ Mice were scored as protected when parasitemia was not observed over a 30-day pariod.

${ }^{\dagger}$ Significant difference in protection rate as compared to none and as calculated by chi-test. NA.: Not applicable.

Results represent pooled data of two independent experiments. 


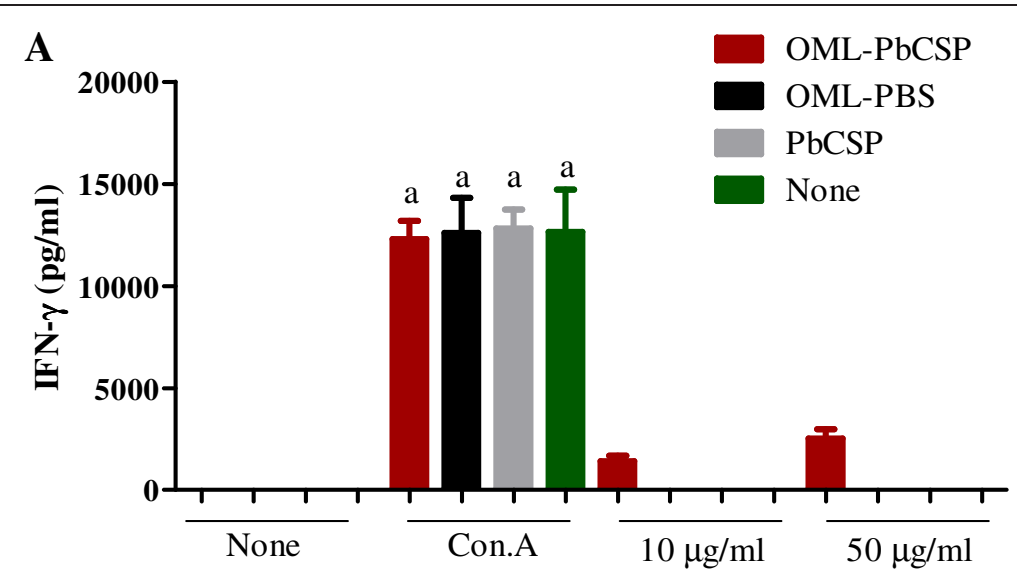

Stimulation

B

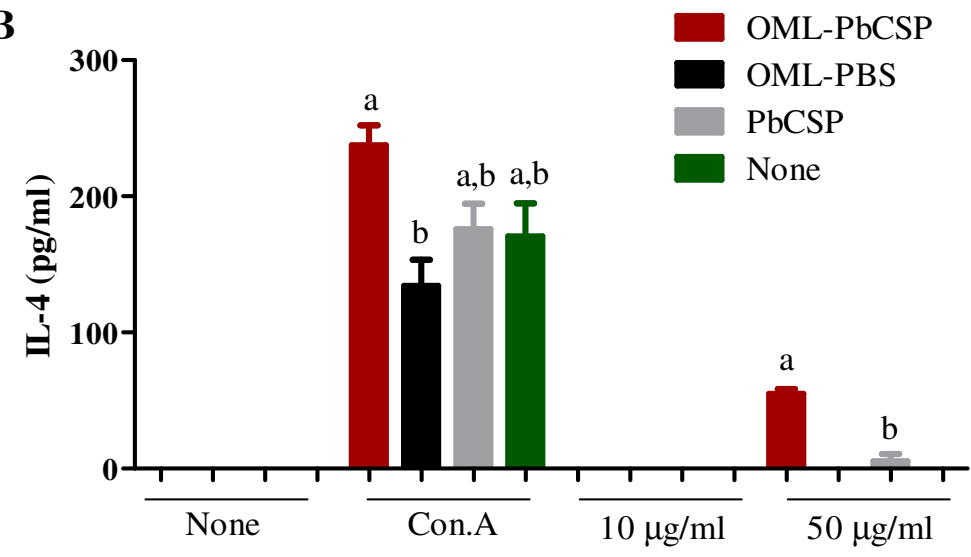

Stimulation

C

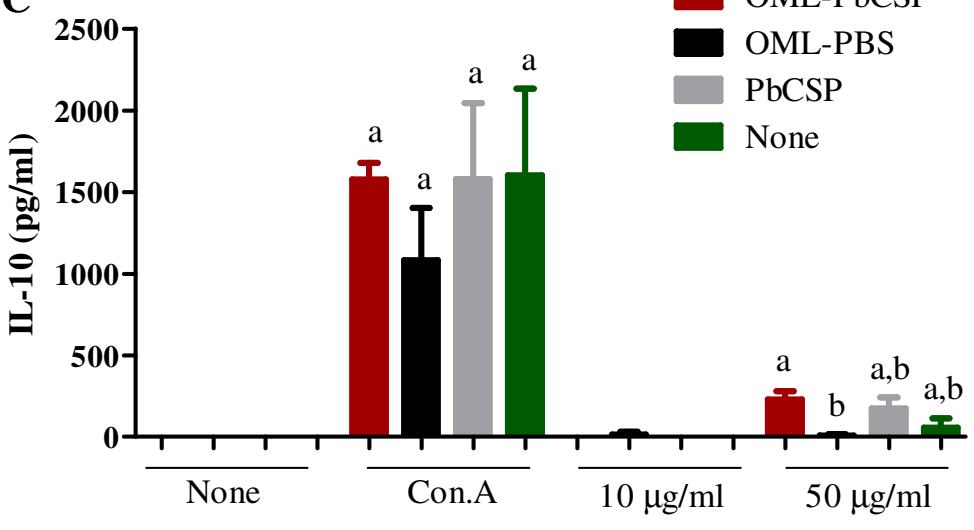

Stimulation

Figure 4 Cytokine detection in splenocyte cultures. To detect IFN- $(\mathbf{A}), I L-4$ (B) and IL-10 (C) production by ELISA, splenocyte cultures for each group of mice $(n=4)$ were prepared and the supernatants were collected after incubation for $48 \mathrm{~h}$ at $37^{\circ} \mathrm{C}$ with the PbCSP antigen $(10 \mathrm{or} 50 \mu \mathrm{g} / \mathrm{ml})$, $0.5 \mu \mathrm{g} / \mathrm{ml}$ of concanavalin A (ConA) or without any stimulus. Each bar represents the mean \pm SD based on four mice per group. Mice were either immunized by OML-PbCSP (OML-PbCSP), OML alone (OML-PBS), naked PbCSP (PbCSP), or not immunized (None). Different superscript letters indicate statistically significant differences $(P<0.05)$ among groups as determined by a one-way analysis of variance followed by Tukey's multiple comparison test. 
rapidly suppress MHC class I and class II presentation of malarial antigens by APCs, thereby preventing the development of protective immunity in vaccinated mice $[27,29]$. A recent study has shown that vaccination of mice with recombinant $P$. berghei schizont egress antigen-1 (PbSEA-1) significantly reduces parasitemia and delays mortality. The authors have concluded that the protection by PbSEA- 1 is due to the function of its specific antibody that decreases the parasite replication by arresting schizont and preventing the egression [30]. In the present study, immunization with OML-PbMSP1 prolonged survival but failed to protect mice against the infection with erythrocytic-stage $P$. berghei. However, immunizations with the OML-PbMSP1 induced the production of antiPbMSP1 IgG1 and IgG2a, which recognized the parasites. Thus, a possibility for lack of protection in this data may be due to the insufficient antibody titer against the parasite infection.

Sterile protection induced by an effective malaria vaccine should lead to the blockade of exoerythrocytic forms retained within hepatocytes and trapped by Kupffer cells, whereas activated CTLs act as effector cells for the elimination of parasitized hepatocytes in the liver $[9,10]$. Moreover, $\mathrm{CD}^{+} \mathrm{T}$ cells seem to contribute to protective immunity in the liver through initiating the responses of $\mathrm{CD}^{+} \mathrm{T}$ effector cells and mediating the production of neutralizing antibodies [31]. Sporozoitespecific antibodies may neutralize malaria parasites and inhibit their invasion into hepatocytes, thereby allowing macrophages and other polymorphonucleocytes to phagocytize extracellular sporozoites [9,10]. In addition, a recent study has shown that sporozoite-specific antibodies are protective and provide sterilizing immunity against malaria infection when reaching or exceeding a critical plasma concentration [32]. In the present study, immunization with OML-based sporozoite antigen induced high humoral responses consisting of IgG1 and IgG2a, and the splenocyte cultures from the OMLPbCSP-immunized mice released the production of IFN- $\gamma$, IL-4 and IL-10 after stimulation with the PbCSP. These results support the concept that OML has adjuvant properties through triggering humoral and cellular responses [15-21]. Strikingly, immunization with OML$\mathrm{PbCSP}$ elicited substantial protection in mice against sporozoite challenge infection. The protection conferred by s.c. immunization with OML-PbCSP may be related to activation of professional APCs by OML; these cells might effectively present $\mathrm{PbCSP}$-derived peptides via MHC class I and class II molecules, which prime specific $\mathrm{CD}^{+}$and $\mathrm{CD} 4^{+}$memory $\mathrm{T}$ cells, respectively [15]. Thus, effector memory $\mathrm{T}$ cells may migrate into the liver and trigger local CTLs that eliminate parasitized hepatocytes following challenge infection with sporozoites. In parallel, PbCSP-specific antibodies might inhibit sporozoite invasion and mediate the clearance of parasites by antibody-dependent-cellular-cytotoxicity. Indeed, the present data revealed some correlation between the protection and the antibody response to PbCSP as evidenced by elevated antibody titers in protected mice over unprotected received same immunization regimen.

Nonetheless, the protection rates observed in the present data were comparable to those in several other immunization trials using murine models of infection. For instance, immunization with the long synthetic polypeptide, $\mathrm{PbCSP}_{242-310}$, coupled with the QS-21 saponin adjuvant resulted in a $60 \%$ level of protection [23]. Administration of recombinant adenylate cyclase toxoid of Bordetella pertussis containing a PbCSP epitope elicited a robust IFN- $\gamma$-producing $\mathrm{T}$ cell response also associated with $60 \%$ protection in mice in the absence of further adjuvant [33]. Additionally, immunization with the repeat epitope of PbCSP and different oil-based adjuvants elicited $29-100 \%$ sterile protection in mice [34]. Genetic vaccination with $\mathrm{PbCSP}$ induced $30-90 \%$ protection in mice against sporozoite and mosquito challenge infections [35]. Likewise, prime-boost vaccinations of the attenuated recombinant poxviruses MVA and FP9 encoding CSP or thrombospondin-related adhesion protein of $P$. berghei, respectively, were shown to confer substantial protection (20-90\%) against liver-stage murine malaria $[7,36]$.

OMLs are preferentially incorporated into macrophages via ICAM-3 grabbing nonintegrin-related 1 (SIGNR1) $[15,37,38]$. Furthermore, the macrophages and DCs also produce IL-12 in response to the preferential uptake of OMLs, leading to antigen-specific Th1 immunity [39]. Thus, the uptake of antigen-encapsulating OMLs by APCs must be an initial key event in the induction of the antigenspecific Th1 immune response. OMLs could be defined as good adjuvant that enhanced the immunogenicity of antigenic vaccine components. In addition, OMLs are very suitable for use as an adjuvant and vehicle for vaccines because they consist of innocuous materials distributed ubiquitously throughout the body and cause no damage to the skin at the injection site [40]. To develop novel type of malaria vaccine, there is a need to evaluate the enhanced protection of OML-based vaccine by using appropriate adjuvant such as alum, cocktail antigens or synthetic peptides formation.

\section{Conclusions}

Immunization with OML-PbCSP elicited substantial protection against liver-stage malaria infection in BALB/C mice. The current approach has potential to provide a novel antigen-delivery system for developing malaria vaccine.

\section{Abbreviations}

OML: Oligomannose-coated liposome; OML-PbMSP1: Plasmodium berghei Merozoite surface protein 1 entrapped with OML; OML-PbCSP: Plasmodium berghei Circumsporozoite protein entrapped with OML; pRBCs: Infected red 
blood cells; APC: Antigen-presenting cell; MHC: Major histocompatibility complex; CTLs: Cytotoxic T lymphocytes; i.p.: Intraperitoneal; s.c.: Subcutaneous; IFN-Y: Interferon gamma; IL-4: Interleukin 4; ELISA: Enzyme-linked immunoabsorbent assay; PBS: Phosphate buffered saline; OD: Optical density; SD: Standard deviation.

\section{Competing interests}

The authors declare that they have no competing interests.

\section{Authors' contributions}

YN and MAT designed the study and prepared this manuscript. MAT, YK, SF, ST, NK performed the experiments. YN and MAT analyzed the results. All authors have read and approved the final manuscript.

\section{Acknowledgements}

We thank Youko Matsushita, Megumi Noda, and Yoshie Imura (National Research Center for Protozoan Diseases, Obihiro University of Agriculture and Veterinary Medicine) for their excellent technical assistance. This research was supported by the Japan Society for the Promotion of Science (JSPS) through the Funding Program for Next-Generation World-Leading Researchers (NEXT Program), initiated by the Council for Science and Technology Policy (2011/LS003).

\section{Author details}

'National Research Center for Protozoan Diseases, Obihiro University of Agriculture and Veterinary Medicine, Inada-cho, Obihiro, Hokkaido 080-8555, Japan. ${ }^{2}$ Department of Applied Biochemistry, Tokai University, Kita-kaname, Hiratsuka, Kanagawa 259-1292, Japan.

Received: 9 August 2014 Accepted: 26 October 2014 Published: 5 November 2014

\section{References}

1. Epstein JE, Tewari K, Lyke KE, Sim BK, Billingsley PF, Laurens MB, Gunasekera A, Chakravarty S, James ER, Sedegah M, Richman A, Velmurugan S, Reyes S, Li M, Tucker K, Ahumada A, Ruben AJ, Li T, Stafford R, Eappen AG, Tamminga C, Bennett JW, Ockenhouse CF, Murphy JR, Komisar J, Thomas N, Loyevsky M, Birkett A, Plowe CV, Loucq C, et al: Live attenuated malaria vaccine designed to protect through hepatic $\mathrm{CD} 8^{+} \mathrm{T}$ cell immunity. Science 2011, 334:475-480

2. Spring M, Murphy J, Nielsen R, Dowler M, Bennett JW, Zarling S, Williams J, de la Vega P, Ware L, Komisar J, Polhemus M, Richie TL, Epstein J, Tamminga C, Chuang I, Richie N, O'Neil M, Heppner DG, Healer J, O'Neill M, Smithers H, Finney OC, Mikolajczak SA, Wang R, Cowman A, Ockenhouse C, Krzych U, Kappe SH: First-in-human evaluation of genetically attenuated Plasmodium falciparum sporozoites administered by bite of Anopheles mosquitoes to adult volunteers. Vaccine 2013, 31:4975-4983.

3. Ballou WR: The development of the RTS, S malaria vaccine candidate: challenges and lessons. Parasite Immunol 2009, 31:492-500.

4. Anders RF: The case for a subunit vaccine against malaria. Trends Parasitol 2011, 27:330-334.

5. Moorthy VS, Ballou WR: Immunological mechanisms underlying protection mediated by RTS,S: a review of the available data. Malar $J$ 2009, 8:312.

6. Brooks A, Briët OJ, Hardy D, Steketee R, Smith TA: Simulated impact of RTS, S/AS01 vaccination programs in the context of changing malaria transmission. PLoS One 2012, 7:e32587.

7. Hill AV, Reyes-Sandoval A, O'Hara G, Ewer K, Lawrie A, Goodman A, Nicosia A, Folgori A, Colloca S, Cortese R, Gilbert SC, Draper SJ: Prime-boost vectored malaria vaccines: progress and prospects. Hum Vaccin 2010, 6:78-83.

8. Sheehy SH, Douglas AD, Draper SJ: Challenges of assessing the clinical efficacy of asexual blood-stage Plasmodium falciparum malaria vaccines. Hum Vaccin Immunother 2013, 9:1831-1840.

9. Thera MA, Doumbo OK, Coulibaly D, Laurens MB, Ouattara A, Kone AK, Guindo AB, Traore K, Traore I, Kouriba B, Diallo DA, Diarra I, Daou M, Dolo A, Tolo Y, Sissoko MS, Niangaly A, Sissoko M, Takala-Harrison S, Lyke KE, Wu Y, Blackwelder WC, Godeaux O, Vekemans J, Dubois MC, Ballou WR, Cohen J, Thompson D, Dube T, Soisson L, et al: A field trial to assess a blood-stage malaria vaccine. N Engl I Med 2012, 365:1004-1013.

10. Schwenk RJ, Richie TL: Protective immunity to pre-erythrocytic stage malaria. Trends Parasitol 2011, 27:306-314.

11. Doolan DL, Martinez-Alier N: Immune response to pre-erythrocytic stages of malaria parasites. Curr Mol Med 2006, 6:169-185.
12. Langhorne J, Ndungu FM, Sponaas AM, Marsh K: Immunity to malaria: more questions than answers. Nat Immunol 2008, 9:725-732.

13. Richards JS, Beeson JG: The future for blood-stage vaccines against malaria. Immunol Cell Biol 2009, 87:377-390.

14. Tyagi RK, Garg NK, Sahu T: Vaccination Strategies against Malaria: novel carrier(s) more than a tour de force. J Control Release 2012, 162:242-254.

15. Kojima N, Biao L, Nakayama T, Ishii M, Ikehara Y, Tsujimura K: Oligomannose-coated liposomes as a therapeutic antigen-delivery and an adjuvant vehicle for induction of in vivo tumor immunity. J Control Release 2008, 129:26-32.

16. Kojima N, Ishii M, Kawauchi Y, Takagi H: Oligomannose-coated liposome as a novel adjuvant for the induction of cellular immune responses to control disease status. BioMed Res Int 2013, 2013:562924-562935.

17. Shimizu Y, Yamakami K, Gomi T, Nakata M, Asanuma H, Tadakuma T, Kojima $\mathrm{N}$ : Protection against Leishmania major infection by oligomannosecoated liposomes. Bioorg Med Chem 2003, 11:1191-1195.

18. Nishikawa $Y$, Zhang $H$, lkehara $Y$, Kojima N, Xuan X, Yokoyama N: Immunization with oligomannose-coated liposome-entrapped dense granule protein 7 protects dams and offspring from Neospora caninum infection in mice. Clin Vaccine Immunol 2009, 16:792-797.

19. Nishimura M, Kohara J, Kuroda Y, Hiasa J, Tanaka S, Muroi Y, Kojima N, Furuoka H, Nishikawa Y: Oligomannose-coated liposome-entrapped dense granule protein 7 induces protective immune response to Neospora caninum in cattle. Vaccine 2013, 31:3528-3535.

20. Zhang H, Nishikawa Y, Yamagishi J, Zhou J, Ikehara Y, Kojima N, Yokoyama $\mathrm{N}$, Xuan X: Neospora caninum: application of apical membrane antigen 1 encapsulated in the oligomannose-coated liposomes for reduction of offspring mortality from infection in BALB/c mice. Exp Parasitol 2010, 125:130-136.

21. Tanaka S, Kuroda Y, Ihara F, Nishimura M, Hiasa J, Kojima N, Nishikawa Y: Vaccination with profilin encapsulated in oligomannose-coated liposomes induces significant protective immunity against Toxoplasma gondii. Vaccine 2014, 32:1781-1785.

22. Wan Omar A, Roslaini AM, Ngah ZU, Azahari AA, Zahedi M, Baharudin O: A recombinant $19 \mathrm{kDa}$ Plasmodium berghei merozoite surface protein 1 formulated with alum induces protective immune response in mice. Trop Biomed 2007, 24:119-126.

23. Meraldi V, Romero JF, Kensil C, Corradin G: A strong CD8+ T cell response is elicited using the synthetic polypeptide from the C-terminus of the circumsporozoite protein of Plasmodium berghei together with the adjuvant QS-21: quantitative and phenotypic comparison with the vaccine model of irradiated sporozoites. Vaccine 2005, 23:2801-2812.

24. Draper SJ, Moore AC, Goodman AL, Long CA, Holder AA, Gilbert SC, Hill F, Hill AV: Effective induction of high-titer antibodies by viral vector vaccines. Nat Med 2008, 14:819-821.

25. Draper SJ, Biswas S, Spencer AJ, Remarque EJ, Capone S, Naddeo M, Dicks MD, Faber BW, de Cassan SC, Folgori A, Nicosia A, Gilbert SC, Hill AV: Enhancing blood-stage malaria subunit vaccine immunogenicity in rhesus macaques by combining adenovirus, poxvirus, and protein-inadjuvant vaccines. J Immunol 2010, 185:7583-7595.

26. Yoshida S, Nagumo H, Yokomine T, Araki H, Suzuki A, Matsuoka H: Plasmodium berghei circumvents immune responses induced by merozoite surface protein 1- and apical membrane antigen 1-based vaccines. PLoS One 2010, 5:e13727.

27. Goodman AL, Forbes EK, Williams AR, Douglas AD, de Cassan SC, Bauza K, Biswas S, Dicks MD, Llewellyn D, Moore AC, Janse CJ, Franke-Fayard BM, Gilbert SC, Hill AV, Pleass RJ, Draper SJ: The utility of Plasmodium berghei as a rodent model for anti-merozoite malaria vaccine assessment. Sci Rep 2013, 3:e1706.

28. Toebe CS, Clements JD, Cardenas L, Jennings GJ, Wiser MF: Evaluation of immunogenicity of an oral Salmonella vaccine expressing recombinant Plasmodium berghei merozoite surface protein-1. Am J Trop Med Hyg 1997, 56:192-199.

29. Lundie RJ, Young LJ, Davey GM, Villadangos JA, Carbone FR, Heath WR, Crabb BS: Blood-stage Plasmodium berghei infection leads to short-lived parasite-associated antigen presentation by dendritic cells. Eur I Immunol 2010, 40:1674-1681.

30. Raj DK, Nixon CP, Nixon CE, Dvorin JD, DiPetrillo CG, Pond-Tor S, Wu HW, Jolly G, Pischel L, Lu A, Michelow IC, Cheng L, Conteh S, McDonald EA Absalon S, Holte SE, Friedman JF, Fried M, Duffy PE, Kurtis JD: Antibodies to 
PfSEA-1 block parasite egress from RBCs and protect against malaria infection. Science 2014, 23:871-877.

31. Tartz S, Deschermeier C, Retzlaff S, Heussler V, Sebo P, Fleischer B, Jacobs T Plasmodium berghei sporozoite challenge of vaccinated BALB/c mice leads to the induction of humoral immunity and improved function of CD8(+) memory T cells. Eur J Immunol 2013, 43:693-704.

32. Foquet $L$, Hermsen $C C$, van Gemert GJ, Van Braeckel E, Weening KE, Sauerwein R, Meuleman P, Leroux-Roels G: Vaccine-induced monoclonal antibodies targeting circumsporozoite protein prevent Plasmodium falciparum infection. J Clin Invest 2014, 124:140-144.

33. Tartz S, Kamanova J, Simsova M, Sebo P, Bolte S, Heussler V, Fleischer B, Jacobs T: Immunization with a circumsporozoite epitope fused to Bordetella pertussis adenylate cyclase in conjunction with cytotoxic T-lymphocyte-associated antigen 4 blockade confers protection against Plasmodium berghei liver-stage malaria. Infect Immun 2006, 74:2277-2285.

34. Reed RC, Louis-Wileman V, Wells RL, Verheul AF, Hunter RL, Lal AA: Re-investigation of the circumsporozoite protein-based induction of sterile immunity against Plasmodium berghei infection. Vaccine 1996, 14:828-836.

35. Weiss R, Leitner WW, Scheiblhofer S, Chen D, Bernhaupt A, Mostböck S, Thalhamer J, Lyon JA: Genetic vaccination against malaria infection by intradermal and epidermal injections of a plasmid containing the gene encoding the Plasmodium berghei circumsporozoite protein. Infect Immun 2000, 68:5914-5919.

36. Hutchings $\mathrm{CL}$, Birkett AJ, Moore AC, Hill AV: Combination of protein and viral vaccines induces potent cellular and humoral immune responses and enhanced protection from murine malaria challenge. Infect Immun 2007, 75:5819-5826.

37. Takagi H, Numazaki M, Kajiwara T, Abe Y, Ishii M, Kato C, Kojima N: Cooperation of specific ICAM-3 grabbing nonintegrin-related 1 (SIGNR1) and complement receptor type 3 (CR3) in the uptake of oligomannosecoated liposomes by macrophages. Glycobiology 2009, 19:258-266.

38. Kawauchi Y, Kuroda Y, Kojima N: Preferences for uptake of carbohydratecoated liposomes by $\mathrm{C}$-type lectin receptors as antigen-uptake receptors. Glycoconj J 2012, 29:481-490

39. Kato C, Kojima N: SIGNR1 ligation on murine peritoneal macrophages induces IL-12 production through NFkappaB activation. Glycoconj J 2010 27:525-531

40. Fukasawa M, Shimizu Y, Shikata K, Nakata M, Sakakibara R, Yamamoto N, Hatanaka M, Mizuochi T: Liposome oligomannosecoated with neoglycolipid, a new candidate for a safe adjuvant for induction of CD8 cytotoxic T lymphocytes. FEBS Lett 1998, 441:353-356.

doi:10.1186/1475-2875-13-426

Cite this article as: Terkawi et al:: Plasmodium berghei circumsporozoite protein encapsulated in oligomannose-coated liposomes confers protection against sporozoite infection in mice. Malaria Journal 2014 13:426.

\section{Submit your next manuscript to BioMed Central and take full advantage of:}

- Convenient online submission

- Thorough peer review

- No space constraints or color figure charges

- Immediate publication on acceptance

- Inclusion in PubMed, CAS, Scopus and Google Scholar

- Research which is freely available for redistribution 